spectra, the complete story of the evolution of suns from the inchoate nebula onwards to the most active sun (like our own), and then downward to the almost heatless and invisible ball. The period during which human life has existed on our globe is probably too short-even if our first parents had begun the work-to afford observational proof of such a cycle of change in any particular star; but the fact of such evolution, with the evidence before us, can hardly be doubted. I most fully believe that, when the modifications of terrestrial spectra under sufficiently varied conditions of temperature, pressure, and environment have been further studied, this conclusion will be greatly strengthened. But in this study we must have regard also to the spectra of the stars themselves. The stars are the crucibles of the Creator. There we see matter under conditions of temperature and pressure and environment, the variety of which we can not hope to emulate in our laboratories, and on a scale of magnitude beside which the proportion of our greatest experiment is less than that of the drop to the ocean. The spectroscopic astronomer has to thank the physicist and the chemist for the foundation of his science, but the time is coming-we almost see it now-when the astronomer will repay the debt by widereaching contributions to the very fundamenta of chemical science.

By patient, long-continued labor in the minute sifting of numerical results, the grand discovery has been made that a great part of space, so far as we have visible knowledge of it, is occupied by two majestic streams of stars traveling in opposite directions. Accurate and minute measurement has given us some certain knowledge as to the distances of the stars within a certain limited portion of space, and in the cryptograms of their spectra has been deciphered the amazing truth that the stars of both streams are alike in design, alike in chemical constitution, and alike in process of development.

But whence have come the two vast streams of matter out of which have been evolved these stars that now move through space in such majestic procession?

The hundreds of millions of stars that comprise these streams, are they the sole ponderable occupants of space? However vast may be the system to which they belong, that system itself is but a speck in illimitable space; may it not be but one of millions of such systems that pervade the infinite?

We do not know.

"Canst thou by searching find out God? canst thou find out the Almighty unto perfection?"'

\section{David GILL}

\section{SCIENTIFIC BOOKS}

$A$ Text-book of Electro-Chemistry. By $\mathrm{M}_{\mathrm{AX}}$ Le Blanc, Professor in the University of Leipzig. Translated from the Fourth German Edition by W. R. Whitney, Ph.D., Director of the Research Laboratory of the General Electric Company, and JoHN W. Brown, Director of the Research and Battery Laboratory of the National Carbon Company. 8vo, pp. $x i v+338$. Price, $\$ 2.60$ net. New York: The Macmillan Company.

That two busy men, immersed to their eyes in solving the commercial problems of two great industrial corporations, should have the courage of their convictions to the extent of themselves translating this splendid textbook, is a most hopeful sign of the times, whichever way it is regarded. What more could be wished, than that a text-book should originate within the classic precincts of a university, and be translated and sponsored by the heads of two commercial laboratories? And the book is worthy of its origin.

The earlier editions of Le Blanc's book are 
so well known to electro-chemists, that but a brief allusion to the contents as a whole is necessary here. The well-balanced chapters deal with the fundamental principles, historical development, theory of electrolytic dissociation, migration of ions, conductance of electrolytes, electrical endosmose and electrostenolysis, electromotive force, electrolysis and polarization, a supplement on accumulators and an appendix describing the scheme of notation employed.

As to the way in which these are handled, the English is above criticism and the presentation is lucid and comprehensible to the last degree. There is nowhere the slightest chance for misunderstanding the writer's ideas, whether one accepts them as a finality or not. As a presentation of the fundamental facts and the prevalent theories of electrochemistry, the work is probably without an equal, certainly without a superior. As prices go, the book is much cheaper than usual-an additional recommendation, probably ascribable to the broad views and sound commercial instincts of the translators and publishers.

As to the plan of the work, the theory of electrolytic dissociation is followed consistently throughout. We regret to say, however, that although so praiseworthy in other respects, the form of statement in terms of the theory is not always free from objection, and to give the student an unbiased, absolutely unobjectionable idea, would need revision by the teacher. To illustrate: "The value 13,700 calories then really represents the heat of dissociation of water" (p. 134). The statement should certainly have been qualified by saying electrolytic dissociation, or even ionization, for dissociation; otherwise, the statement as it stands, is certainly incorrect.

A series of inconsistencies is caused by following in too uncritical a spirit the teachings of the dissociation theory. Thus, on page 94 we have:

The degree of dissociation of a substance in solution is equal to the ratio of its equivalent conductance in that solution to its equivalent conductance in a solution of infinite volume.

But on page 148, discussing the di-electric constants of solvents, we have:

From this fact it follows that it is inadmissible to draw a conclusion, as often has been done, regarding the degree of dissociation from the value of the equivalent conductance alone.

Such inconsistencies (and there are others of analogous character) are the chief defects of the book. The tenets of the dissociation theory are laid down with emphasis, usually in italics, as above, and then later the experimental facts which negative some of those statements are either not mentioned, or mentioned with very slight emphasis, or else freely admitted, and yet their full import and effect glossed over. There is in many cases an apparent willingness to admit facts contrary to the tenets of the dissociation theory, and yet such facts are not pushed to their full, legitimate conclusion.

All of this shows that the theories of electrochemistry are in a state of transition; even the teachers with the best of purposes to see all sides are sometimes staring at one side and blinking at the other. The perfectly judicial attitude of mind is, at present, difficult if not impossible to preserve. A few years will see a new era of electrochemical theory and teaching, wherein the student is nurtured as a plain eclectic, keen to see and quick to admit the truth wherever and in whatever guise he finds it.

Are we speaking of an unattainable millennium? We hope not.

\section{JoSEPH W. RichaRdS}

\section{Tropical Medicine. Вy Thomas W. JACKson,} M.D.

The acquisition by this government within the last few years of the Philippine Islands, Puerto Rico and the Panama Canal District, and its necessary sanitary supervision over Cuba in its relation to yellow fever, have made the study of tropical diseases one of great interest and, especially for the physicians of the southern states, one of practical necessity, for as our knowledge of these so-called tropical 